\title{
FEEDING INTOLERANCE IN A PATIENT WITH ADVANCED PARKINSON'S DISEASE AND VASCULAR DEMENTIA: LESSONS LEARNT
}

Dr Michael Warren Lim, Dr Jeffrey Jiang Song En

\section{SFP2019; 45(5) : 45-49}

\section{INTRODUCTION}

Mdm $\mathrm{N}$ is an 80-year-old Chinese female with advanced Parkinson's Disease (PD) and vascular dementia (VaD) who was admitted to a community hospital for management of her sacral ulcer. She was bed-bound and non-communicative and had been initiated on nasogastric tube (NGT) feeding since 2009. Over her prolonged inpatient stay for wound care, numerous difficulties were encountered in her NGT feeding requiring frequent adjustment of her feeding regime. This led to difficulties with her long-term placement even after her sacral ulcer had healed.

Through this case, we illustrate the challenges encountered in patients on long-term tube feeding (TF), measures that were taken to optimise her nutrition and how these challenges had a bearing on her long-term care.

\section{PATIENT'S REVELATION}

"Doctor, why do my mother's feeds keep getting stopped? She is getting skinnier every day!" Mdm N's son asked as yet another syringe of milky undigested feeds was aspirated from her NGT.

\section{Case History}

Mdm N has been bed-bound, non-communicative and dependent in her Activities of Daily Living (ADLs) since 2015 due to advanced PD and VaD. Her PD symptoms were noted since 2006 when she developed bradykinesia, increased muscle rigidity, constipation and recurrent falls causing progressive functional decline. She was also noted to have cognitive impairment from 2006 and was diagnosed with VaD after work up by a neurologist.

Her functional status continued to decline from 2006 despite treatment with levodopa and galantamine for $\mathrm{PD}$ and $\mathrm{VaD}$ respectively. She was wheelchair-bound by 2008 and subsequently bed-bound and ADL-dependent by 2015. Oropharyngeal dysphagia was noted after a subcortical stroke in 2009, and she was started on enteral nutrition (EN) via nasogastric tube(NGT) feeding and has been on regular dietician follow-up since then. Her medical history and functional status are summarised in Figure 1.

\section{Dr Michael Warren Lim}

Resident, Department of Family Medicine,

National University Health System

\section{Dr Jeffrey Jiang Song En}

Registrar, St Luke's Hospital

\section{Figure 1: Summary of Mdm N's Medical History and Functional Status}

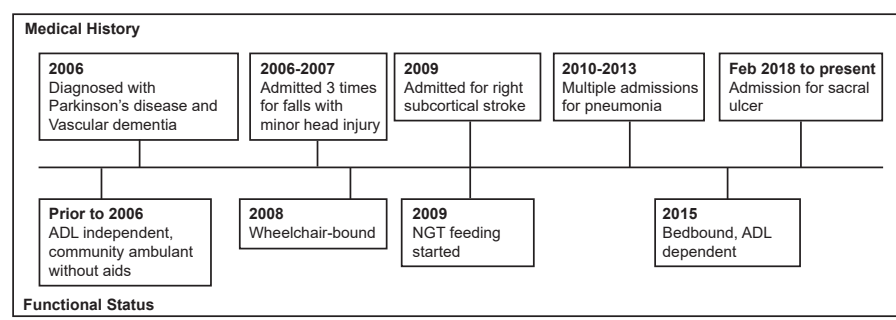

Her past medical history included previous trans-sphenoidal resection and radiotherapy for a non-functional pituitary adenoma in 2000 following which she required lifelong thyroxine and hydrocortisone replacement. Her other medications include levodopa-benserazide (Madopar), esomeprazole and lactulose.

Throughout this, her family had been highly supportive of her care. She was looked after at home by her husband, her youngest son and adomestic helper together with support from dietetics services in adjusting her feeding regime. An Advance Care Planning (ACP) discussion was previously planned during a previous admission in another institution in 2017 but did not take place due to the absence of some family members.

From October 2017, she was noted to have intolerance to her EN as manifested by high Gastric Residual Volumes (GRV), requiring various trials of more concentrated feeds to decrease feeding volume while meeting her caloric and protein requirements.

She was admitted to an acute hospital in February 2018 for a large unstageable sacral ulcer and was subsequently transferred to a community hospital for wound care. She was noted to be persistently intolerant of her EN as evidenced by high GRVs despite frequent adjustments of her feeding regime.

\section{Physical Examination}

Mdm N was a $49 \mathrm{~kg}$ woman who was cachectic and dehydrated. Her vital signs were normal. She was able to open her eyes occasionally but unable to communicate through words or gestures. Her abdomen was soft, non-distended and non-tender without any palpable masses. Bowel sounds were normal and no succussion splash could be elicited. On neurological examination, she had flexion contractures of both upper and lower limbs with lead-pipe rigidity and cogwheeling tone in both upper limbs. Examination of the skin noted a deep $5.3 \times 4.6 \mathrm{~cm}$ unstageable ulcer on the sacral region with erythema of surrounding skin. Additional areas of redness were noted over bony prominences at the left hip and both heels.

\section{Medical Issues}

1. Intolerance to EN manifested by high GRVs, likely due to gastroparesis from advanced PD causing malnutrition

2. Large sacral ulcer 
3. Advanced PD and VaD complicated by oropharyngeal dysphagia requiring NGT feeding

\section{Social Issues}

1. Mdm N's family was increasingly burdened by her care requirements despite their best efforts. The family's search for a Nursing Home (NH) was also hindered by feeding difficulties which most NHs were unable to handle.

\section{GAINING INSIGHT}

In managing $\mathrm{Mdm} \mathrm{N}$, the following questions arose:

1. Why was Mdm $\mathrm{N}$ unable to tolerate her EN?

2. How can we optimise Mdm N's nutrition despite the issues encountered with her EN?

3. What are the long-term care options for $\mathrm{Mdm} \mathrm{N}$ ?

\section{MANAGEMENT}

\section{Why was Mdm $\mathrm{N}$ unable to tolerate her EN?}

Gastrointestinal dysfunction is frequently observed in patients with PD and includes symptoms such as drooling, dysphagia, impaired gastric motility (gastroparesis)and constipation ${ }^{1}$. In Mdm N's case, it was postulated that her feeding intolerance was due to gastroparesis, which is thought to affect between 70-100 percent of patients with $\mathrm{PD}^{2}$. Gastroparesis manifests as nausea, reduced appetite, early satiety, bloating, vomiting and weight loss ${ }^{3}$.These symptoms are thought to worsen in advanced $\mathrm{PD}^{4}$.In addition to hindering nutrition, gastroparesis in $\mathrm{PD}$ is also known to interfere with levodopa pharmacokinetics by decreasing small intestinal absorption and contributing to motor fluctuations ${ }^{5}$.

Reversible causes of gastroparesis were excluded - her thyroid function tests, fasting glucose and electrolytes including calcium and potassium were normal. Structural causes of gastric outlet obstruction were considered, for which a referral to a gastroenterologist was sought for further work up.

\section{How can we optimise Mdm N's nutrition despite the issues encountered with her feeding?}

Mdm $\mathrm{N}$ was managed by a multidisciplinary team including medical, nursing, dietetics and medical social work staff. A family conference was organised to understand the family's Ideas, Concerns and Expectations (ICE), to determine the goals of care and to conduct Advance Care Planning (ACP). In view of the patient's frail premorbid state, the family was keen to optimise the patient's nutrition, facilitate sacral ulcer healing and maximise the patient's comfort. Invasive investigations and management were not desired. The patient was referred to a gastroenterologist and invasive work up including oesophagogastro-duodenoscopy (OGD) was considered to exclude anatomical causes of high GRV, but in view of the goals of care this was not pursued. While post-pyloric feeding via nasojejunal tube(NJT) insertion and percutaneous endoscopic transgastric jejunostomy (PEG-J)were options for the treatment of refractory gastroparesis $^{6}$, they were also not in line with her goals of care. As domperidone was unsuccessful in improving the patient's feeding tolerance, on the gastroenterologist's advice, a trial of metoclopramide was successful in lowering GRVs and a decreased frequency of skipped feeds. The patient was monitored closely for the worsening of Parkinsonian features while on metoclopramide, given its potential to worsen Parkinsonism.

More expensive energy-dense feeds were required to maximise protein and calorie intake while minimising feed volume. Due to her intolerance of bolus NGT feeding, the decision was made to switch the patient over to continuous NGT feeding via enteral pump with some success. Her NGT feeding regime during the admission is summarised in Figure 2.

Nursing staff assisted with wound care, feeding and regular monitoring of GRV. As the patient was taking levothyroxine, continuous NGT feeding had to be interrupted before administration of levothyroxine to avoid interfering with its absorption ${ }^{7}$. With nutritional optimization and meticulous wound care, the patient's sacral ulcer healed after several months in our institution.

\section{What are the long-term care options for $\mathrm{Mdm} \mathrm{N}$ ?}

Most NHs are not able to handle the nursing workload of continuous NGT feeding, thus limiting her placement options. The family was also unable to handle the burden of caring for her at home despite maximal support.The options for placement are outlined in Figure 3. Due to Mdm N's high care requirements, she was placed in a Chronic Sick Unit (CSU).

During the Advance Care Planning (ACP) discussion, it was noted that $\mathrm{Mdm} \mathrm{N}$ herself did not express any preferences for her care, and that the last verbal communication the family has had with the patient was 12 years prior to her current admission. The content of the ACP discussion included the family's preference for place of care and extent of interventions in case of deterioration, as outlined in Figure 4.

\section{DISCUSSION}

Optimising nutrition in a malnourished bed bound patient with pressure ulcers

$\mathrm{Mdm} \mathrm{N}$ is at high risk for developing pressure ulcers as she is bed bound and underweight. Her frequent interruption of EN due to intolerance caused a protein-calorie deficit which is an additional risk factor ${ }^{8,9}$. Optimising nutrition, meticulous wound care, pressure offloading and treatment of superimposed infection are key interventions to facilitate ulcer healing ${ }^{10}$. Patients with wounds have a caloric requirement of 30-35 kcal/kg/day (increased to $35-40 \mathrm{kcal} / \mathrm{kg} / \mathrm{day}^{9-11}$ in underweight patients)and a protein requirement of $1.2-1.5 \mathrm{~g} / \mathrm{kg} /$ day. $\mathrm{Mdm}$ N's gastroparesis posed a considerable challenge in achieving this target, requiring a combination of gastrointestinal prokinetic agents, low-volume energy-dense feeds and continuous NGT feeding.

\section{Gastric residual volume (GRV) monitoring and enteral feeding (EN) intolerance}

Mdm N was monitored regularly for signs of feeding intolerance, including abdominal distension, vomiting, diarrhoea and dehydration. Our institution's protocol is to measure GRV prior to each feed, with feeding held if it exceeded $100 \mathrm{mls}$. In Mdm N's case, the frequent occurrence of a high GRV led to omissions of bolus NGT feeds or delays in continuous feeding, causing difficulties in achieving nutrition targets. 
Despite being widely used as a marker of gastric emptying and hence aspiration risk, the effectiveness of GRV monitoring has been questioned. Numerous studies on patients receiving EN in a critical care setting found GRV to be a poor marker of aspiration and pneumonia risk ${ }^{12}$, while trials of delivering EN without GRV monitoring showed no difference in rates of pneumonia while allowing increased feeding volumes ${ }^{13,14}$. Based on this evidence, the latest American College of Gastroenterology Clinical Guidelines recommended against routine GRV monitoring ${ }^{15}$.

In Mdm N's case, a strategy observing for clinical signs of feeding intolerance without monitoring GRV may increase the success of EN. However, it is yet to be determined if these findings are applicable to patients with a neurological cause of gastroparesis and in a general ward setting.

\section{The use of tube feeding (TF) in patients with advanced dementia}

Mdm N has been fed via NGT since 2009 due to the perceived aspiration risk of feeding orally. The question arises of whether this practice is in line with her disease trajectory and overall goals of care. The weight of evidence shows that TF does not prevent and may even increase the chance of aspiration pneumonia ${ }^{16}$ and is associated with increased risk of pressure ulcers ${ }^{17}$ and mortality ${ }^{18,19}$. Most guidelines do not recommend the use of TF for older adults with advanced dementia ${ }^{20,21}$.

Given that Mdm N's family has become accustomed to feeding her via NGT, her present difficulties with feeding even on her NGT and the near-term goal of healing her sacral ulcer, the option of withdrawing NGT feeding was not considered. However, should her condition continue to deteriorate, the option could be brought up as part of her ongoing review of her goals of care.

\section{Right-siting of patients with complex care requirements}

Mdm N's need for continuous NGT feeding requires roundthe-clock monitoring and specialised nursing care which most nursing homes $(\mathrm{NH})$ are not equipped to handle. The team thus had limited options in obtaining long-term placement for the patient. With Singapore's rapidly ageing population ${ }^{22}$, the proportion of patients with long-term care needs is set to increase. Among them will include patients with complex care requirements including tracheostomy care, enteral pump management and non-invasive ventilation. Currently, most of these patients are cared for in Chronic Sick Units (CSUs). It is conceivable that the demand for complex nursing care will increase, requiring additional CSU places or the expansion of the capabilities of existing NHs.

\section{Advance Care Planning (ACP) for patients with progressive neurodegenerative disease}

Mdm N's case illustrates the importance of ACP in patients with progressive neurological diseases such as Parkinson's disease and dementia. With the increasing prevalence of such conditions, all doctors should be equipped to initiate ACP discussions when appropriate. Patients with such conditions tend to deteriorate gradually over years, making it difficult to identify the right moment to initiate ACP discussions ${ }^{23}$. Significant friction can hinder effective discussion on goals of care, arising from factors including avoidance of discussing end of life issues, difficulties in prognosticating survival ${ }^{24-27}$, uncertainty and conflicts of opinion between patients and their caregivers ${ }^{28}$ and the loss of patients' mental capacity. Nevertheless, it is critical for doctors to actively overcome this friction and seek out appropriate moments to initiate the ACP process with these patients to improve end of life care, patient and family satisfaction and reduce stress and anxiety in surviving relatives ${ }^{29}$.

\section{CONCLUSION}

Mdm N's case highlights the complexity of caring for bed bound elderly patients with multiple comorbidities, in particular the difficulty in meeting nutrition targets in patients with gastroparesis due to chronic neurological disease. Inputs were required from a multidisciplinary team, including doctors, nurses, dieticians and medical social workers. Ultimately, her care was optimized in an individualised approach in line with her family's goals of care, with the complexity of her care requirements requiring her eventual placement in a Chronic Sick Unit.

\section{REFERENCES}

1 Fasano A, Visanii NP, Liu LW, Lang AE, Pfeiffer RF. Gastrointestinal dysfunction in Parkinson's disease. The Lancet Neurology. 2015 Jun 1;14(6):625-39.

2 Heetun ZS, Quigley EM. Gastroparesis and Parkinson's disease: a systematic review. Parkinsonism \& related disorders. 2012 Jun 1;18(5):433-40.

3 Pfeiffer RF. Gastrointestinal dysfunction in Parkinson's disease. Current treatment options in neurology. 2018 Dec 1;20(12):54.

4 Goetze O, Wieczorek J, Mueller T, Przuntek H, Schmidt WE, Woitalla D. Impaired gastric emptying of a solid test meal in patients with Parkinson's disease using 13C-sodium octanoate breath test. Neuroscience letters. 2005 Mar 3;375(3):170-3.

5 Kurlan R, Rothfield KP, Woodward WR, Nutt JG, Miller C, Lichter D, Shoulson I. Erratic gastric emptying of levodopa may cause "random" fluctuations of parkinsonian mobility. Neurology. 1988 Mar 1;38(3):419-

6 Camilleri M, Parkman HP, Shafi MA, Abell TL, Gerson L. Clinical Guideline: Management of Gastroparesis. Am J Gastroenterol. 2013; 108:18-37.

7 Wenzel KW, Kirschsieper HE. Aspects of the absorption of oral L-thyroxine in normal man. Metabolism. 1977 Jan 1;26(1):1-8.

8 Thomas DR. Improving outcome of pressure ulcers with nutritional interventions: a review of the evidence. Nutrition. $2001 \mathrm{Feb}$ 1;17(2):121-5.

9 Dorner B, Posthauer ME, Thomas D. The role of nutrition in pressure ulcer prevention and treatment: National Pressure Ulcer Advisory Panel white paper. Advances in skin \& wound care. 2009 May 1;22(5):212-21.

10 Arnold M, Barbul A. Nutrition and wound healing. Plastic and reconstructive surgery. 2006 Jun 1;117(7S):42S-58S.

11 Stechmiller JK. Understanding the role of nutrition and wound healing. Nutrition in clinical practice. $2010 \mathrm{Feb} ; 25(1): 61-8$

12 McClave SA, Lukan JK, Stefater JA, Lowen CC, Looney SW, Matheson PJ, Gleeson K, Spain DA. Poor validity of residual volumes as a marker for risk of aspiration in critically ill patients. Critical care medicine. 2005 Feb 1;33(2):324-30.

13 Reignier J, Mercier E, Le Gouge A, Boulain T, Desachy A, Bellec F, Clavel M, Frat JP, Plantefeve G, Quenot JP, Lascarrou JB. Effect of not monitoring residual gastric volume on risk of ventilator-associated pneumonia in adults receiving mechanical ventilation and early enteral feeding: a randomized controlled trial. Jama. 2013 Jan 16;309(3):249-56.

14 Poulard F, Dimet J, Martin-Lefevre L, Bontemps F, Fiancette M, Clementi E, Lebert C, Renard B, Reignier J. Impact of not measuring residual gastric volume in mechanically ventilated patients receiving early enteral feeding: A prospective before-after study. Journal of Parenteral and Enteral Nutrition. 2010 Mar;34(2):125-30.

15 McClave SA, DiBaise JK, Mullin GE, Martindale RG. ACG clinical guideline: nutrition therapy in the adult hospitalized patient. The American journal of gastroenterology. 2016 Mar;111(3):315. 
16 Finucane TE, Bynum JP. Use of tube feeding to prevent aspiration pneumonia. The Lancet. 1996 Nov 23;348(9039):1421-4.

17 Teno JM, Gozalo P, Mitchell SL, Kuo S, Fulton AT, Mor V. Feeding tubes and the prevention or healing of pressure ulcers. Archives of internal medicine. 2012 May 14;172(9):697-701.

18 Mitchell SL, Kiely DK, Lipsitz LA. The risk factors and impact on survival of feeding tube placement in nursing home residents with severe cognitive impairment. Archives of Internal Medicine. 1997 Feb 10;157(3):327-32.

19 Mitchell SL, Kiely DK, Lipsitz LA. Does artificial enteral nutrition prolong the survival of institutionalized elders with chewing and swallowing problems? The Journals of Gerontology Series A: Biological Sciences and Medical Sciences. 1998 May 1;53(3):M207-13.

20 American Geriatrics Society Ethics Committee and Clinical Practice and Models of Care Committee. American Geriatrics Society feeding tubes in advanced dementia position statement. Journal of the American Geriatrics Society. 2014 Aug;62(8):1590-3.

21 Volkert D, Berner YN, Berry E, Cederholm T, Bertrand PC, Milne A, Palmblad J, Sobotka L, Stanga Z, Lenzen-Grossimlinghaus R, Krys U. ESPEN guidelines on enteral nutrition: geriatrics. Clinical nutrition. 2006 Apr 1;25(2):330-60

$22 \mathrm{Ng} \mathrm{K}$. Singapore feeling impact of rapidly ageing population. Today [Internet] 01 July 2015. Available from: https://www.todayonline.com/singapore/singapore-feeling-impactrapidly-ageing-population [Accessed 27 May 2019]

23 Murray SA, Kendall M, Mitchell G, Moine S, Amblàs-Novellas J, Boyd K. Palliative care from diagnosis to death. Bmj. $2017 \mathrm{Feb} 27 ; 356$ : j878.

24 Ryan T. The advance care planning experiences of people with dementia, family caregivers and professionals: a synthesis of the qualitative literature. Annals of palliative medicine. 2017 Jul 18;6(4):380-9.

25 Robinson L, Dickinson C, Bamford C, Clark A, Hughes J, Exley C. A qualitative study: professionals' experiences of advance care planning in dementia and palliative care, 'a good idea in theory but.... Palliative medicine. 2013 May;27(5):401-8.

26 De Vleminck A, Houttekier D, Pardon K, Deschepper R, Van Audenhove C, Vander Stichele R, Deliens L. Barriers and facilitators for general practitioners to engage in advance care planning: a systematic review. Scandinavian journal of primary health care. $2013 \mathrm{Dec}$ $1 ; 31(4): 215-26$.

27 Michael N, O'Callaghan C, Sayers E. Managing 'shades of grey': a focus group study exploring community-dwellers' views on advance care planning in older people. BMC palliative care. 2017 Dec;16(1):2

28 Lamahewa K, Mathew R, Iliffe S, Wilcock J, Manthorpe J, Sampson EL, Davies N. A qualitative study exploring the difficulties influencing decision making at the end of life for people with dementia. Health Expectations. 2018 Feb;21(1):118-27.

29 Detering KM, Hancock AD, Reade MC, Silvester W. The impact of advance care planning on end of life care in elderly patients: randomised controlled trial. Bmj. $2010 \mathrm{Mar}$ 24;340:c1345.
Figure 2: Mdm N's NGT Feeding Regime

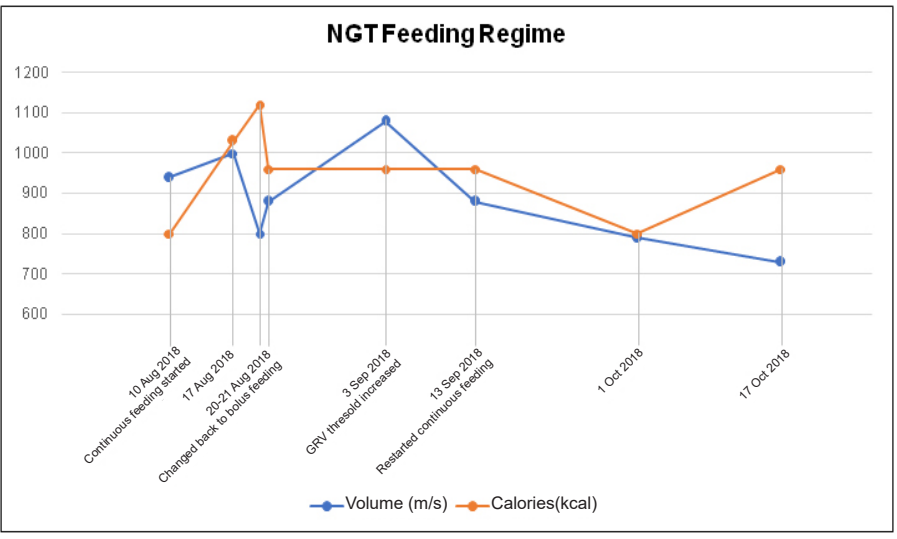

\begin{tabular}{|c|c|c|c|c|c|}
\hline Date & NGT Feeding Regime & $\begin{array}{l}\text { Volume } \\
(\mathrm{mls})\end{array}$ & $\begin{array}{l}\text { Calories } \\
(\mathrm{kcal})\end{array}$ & $\begin{array}{l}\text { Protein } \\
(\mathrm{g})\end{array}$ & Remarks \\
\hline $\begin{array}{l}10 \text { Aug } \\
2018\end{array}$ & $\begin{array}{l}\text { Continuous NGT feeding } \\
\text { Nepro HP* } 440 \mathrm{ml} \\
@ 30 \mathrm{ml} / \mathrm{h} \text { over } 15 \mathrm{~h} \\
\text { Water } 500 \mathrm{ml} \text { over } 5 \text { flushes }\end{array}$ & 940 & 800 & 36 & $\begin{array}{l}\text { High GRV noted, } \\
\text { multiple omitted } \\
\text { feeds - decision } \\
\text { to try continuous } \\
\text { NGT feeding }\end{array}$ \\
\hline $\begin{array}{l}17 \text { Aug } \\
2018\end{array}$ & $\begin{array}{l}\text { Continuous NGT feeding } \\
\text { Nepro HP* } 500 \mathrm{ml} \\
@ 35 \mathrm{ml} \text { over } 15 \mathrm{~h} \\
\text { Propass } 1 \text { scoop } 4 \mathrm{x} / \mathrm{d} \\
\text { Water } 500 \mathrm{ml} \text { over } 5 \text { flushes }\end{array}$ & 1000 & 1030 & 65 & $\begin{array}{l}\text { Volume increased } \\
\text { as feeds tolerated }\end{array}$ \\
\hline $\begin{array}{l}20 \text { Aug } \\
2018\end{array}$ & $\begin{array}{l}\text { Nepro } \mathrm{HP}^{\star} 550 \mathrm{ml} \text { over } 5 \text { feeds } \\
\text { Propass } 1 \text { scoop } 4 \mathrm{x} / \mathrm{d} \\
\text { Water } 250 \mathrm{ml} \text { over } 5 \text { flushes }\end{array}$ & 800 & 1121 & 69 & $\begin{array}{l}\text { Switched to bolus } \\
\text { feeding due to } \\
\text { resource limitation }\end{array}$ \\
\hline $\begin{array}{l}21 \text { Aug } \\
2018\end{array}$ & $\begin{array}{l}\text { Resource } 2.0^{* *} 480 \mathrm{ml} \text { over } \\
4 \text { feeds } \\
\text { Water } 400 \mathrm{ml} \text { over } 4 \text { flushes }\end{array}$ & 880 & 960 & 40 & $\begin{array}{l}\text { Switched to } \\
\text { Resource } 2.0 \text { due } \\
\text { to high GRV noted }\end{array}$ \\
\hline $\begin{array}{l}3 \text { Sep } \\
2018\end{array}$ & $\begin{array}{l}\text { Resource } 2.0^{* *} 480 \mathrm{ml} \text { over } \\
6 \text { feeds } \\
\text { Water } 600 \mathrm{ml} \text { over } 6 \text { flushes }\end{array}$ & 1080 & 960 & 40 & $\begin{array}{l}\text { GRV threshold } \\
\text { for holding feed } \\
\text { increased to } \\
100 \mathrm{mls}\end{array}$ \\
\hline $\begin{array}{l}13 \text { Sep } \\
2018\end{array}$ & $\begin{array}{l}\text { Continuous NGT feeding } \\
\text { Resource } 2.0^{* *} 480 \mathrm{ml} \\
@ 30 \mathrm{ml} / \mathrm{h} \text { over } 16 \mathrm{~h} \\
\text { Water } 400 \mathrm{ml} \text { over } 4 \text { flushes }\end{array}$ & 880 & 960 & 40 & $\begin{array}{l}\text { Continuous NGT } \\
\text { feeding resumed } \\
\text { due to high GRV } \\
\text { and suboptimal } \\
\text { tolerance }\end{array}$ \\
\hline $\begin{array}{l}1 \text { Oct } \\
2018\end{array}$ & $\begin{array}{l}\text { Continuous NGT feeding } \\
\text { Nepro HP* } 440 \mathrm{ml} \\
@ 25 \mathrm{ml} / \mathrm{h} \text { over } 18 \mathrm{~h} \\
\text { Water } 350 \mathrm{ml} \text { over } 4 \text { flushes }\end{array}$ & 790 & 800 & 36 & $\begin{array}{l}\text { Feeding rate and } \\
\text { volume decreased } \\
\text { due to high GRV } \\
\text { and suboptimal } \\
\text { tolerance }\end{array}$ \\
\hline $\begin{array}{l}17 \mathrm{Oct} \\
2018\end{array}$ & $\begin{array}{l}\text { Continuous NGT feeding } \\
\text { Resource } 2.0^{* *} 480 \mathrm{ml} \\
@ 27 \mathrm{ml} / \mathrm{h} \text { over } 18 \mathrm{~h} \\
\text { Water } 250 \mathrm{ml} \text { over } 4 \text { flushes }\end{array}$ & 730 & 960 & 40 & $\begin{array}{l}\text { Changed to } \\
\text { Resource } 2.0 \text { due } \\
\text { to lower cost }\end{array}$ \\
\hline
\end{tabular}

Nutritional content (per 100mls)

${ }^{*}$ Nepro HP (Abbott Laboratories) - Energy $182 \mathrm{kcal}$, protein 8.1

${ }^{* *}$ Resource 2.0 (Nestle Health Science) - Energy $200 \mathrm{kcal}$, protein $8.3 \mathrm{~g}$ 


\section{Figure 3. Placement Options for Mdm N}

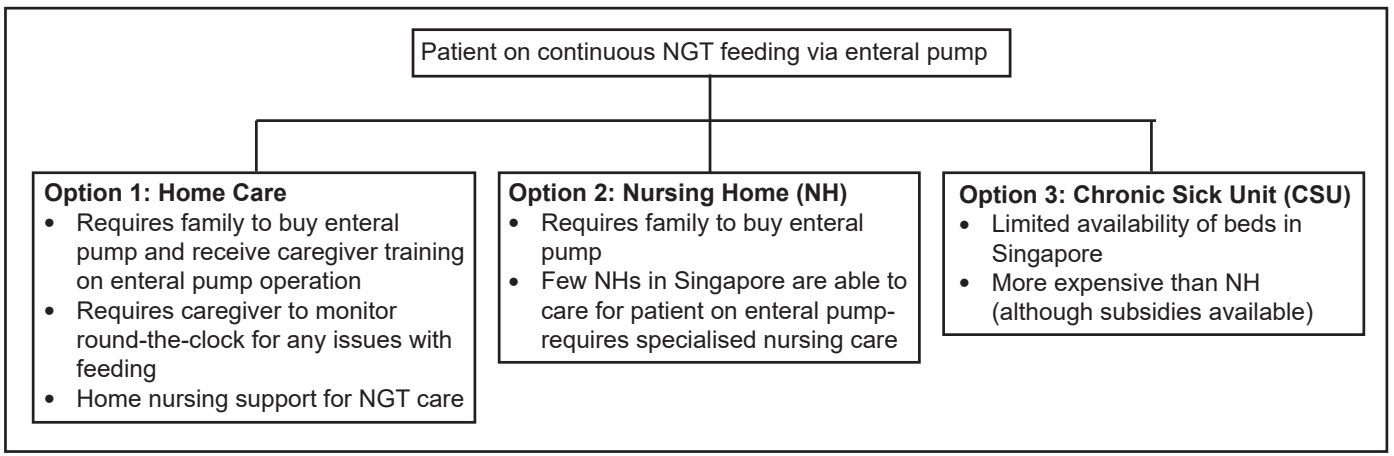

\section{Figure 4. ACP Discussion with Mdm N's Family}

\begin{tabular}{|l|l|}
\hline \multicolumn{2}{|l|}{ Advance Care Planning Discussion with Mdm N's Family } \\
\hline Perferred Place of Care & Chronic Sick Unit \\
\hline Feeding Method & Continuous NGT Feeding \\
\hline $\begin{array}{l}\text { Extent of Intervention in } \\
\text { case of Deterioration }\end{array}$ & $\begin{array}{l}\text { Comfort care } \\
\text { Limited of oral antibiotics in case of infection but } \\
\text { not for further escalation } \\
\text { No transfer to acute hospital } \\
\text { No resuscitative measures e.g. intranvenous fluids, } \\
\text { cardiopulmonary resuscitation, defibrillation, } \\
\text { endotracheal intubation }\end{array}$ \\
\hline Preferred Place of Death & $\begin{array}{l}\text { Home - if logistically feasible and with home hospice } \\
\text { support if necessary }\end{array}$ \\
\hline
\end{tabular}


Authors are invited to submit articles for publication in The Singapore Family Physician on the understanding that the work is original and that it has not been submitted or published elsewhere. Your original article will be considered for publication on the understanding that they have to be approved by the Editorial Board via a double-blinded peer-review process and subject to revision. Authors are encouraged to consult the recommendations in the Uniform Requirements for Manuscripts Submitted to Biomedical Journals (http://www.icmje.org/index.html) which the SFP is in accord with.

The following types of articles may be suitable for publication: case reports/ study, original research works, audits of patient care, protocols for patient or practice management and letters to the Editor. The CME and review articles will be published under the prerogative of the Institute of Family Medicine (IFM) in the College of Family Physicians Singapore. The article has no word limit and should be written in British English. This must be submitted in an electronic form and of a format that is compatible with major word processor applications. Submissions in Microsoft Word format is preferred.

\section{RECOMMENDED FORMAT FOR THE MANUSCRIPT}

The submission should comprise of the following:

I. Title Page

2. Summary/Abstract

3. KeyWords

4. Text/Manuscript

5. Tables

6. Illustrations

7. Learning Points

Authors are advised to ensure the anonymity of study subjects and patients by removing any and all information that could compromise their privacy from the submission.

The text should be typed in Arial font, 12-point size with a 1.5 line space.

\section{The Title Page}

- The title should be concise and highlight the key elements of the article.

- Include on the title page first name, qualifications, present appointments, type and place of practice of each contributor.

- Include name, address, handphone number and email address of the first author to whom correspondence should besent.

- Insert at the bottom: name and address of institution or practice from which the work originated.

\section{Abstract}

- The summary should describe why the article was written and present the main argument or findings.

- Limit words as follows: 250 words for major articles; 200 words for case reports.

- All Original articles (examples: randomised controlled trials, cohort studies, observational studies, and review articles) must be accompanied by a structured abstract while all other categories of manuscripts (examples: PRISM and Case Records of Family Medicine) should have unstructured abstracts.

- Structured - Organise the abstract according to the following headings:

I. Introduction - states the purposes/aims of the study/investigation

2. Methods - describes the selection of study subjects/experimental animals, observational and analytical methods

3. Results - provides specific data and its statistical significance, if possible

4. Conclusion - succinct emphasis of new and important aspects of the study or observations

\section{Key Words}

- Add, at the end of summary in alphabetical listing, keywords of up to 5 in number which will be used for article indexing and retrieval under Medical Subject Headings or MeSH. MeSH is the NLM controlled vocabulary thesaurus used for indexing articles for WPRIM and PubMed. Please refer towww.nlm.nih.gov/mesh/fordetails.

\section{The Text/ Manuscript (full complete)}

The text should have the following sequence:

- Introduction: State clearly the purpose of the article Summarise the rationale for the study or observation. Give only strictly pertinent information and references, and do not review the subject extensively. Provide a context or background for the study (that is, the nature of the problem and its significance). Cite only directly pertinent references, and do not include data or conclusions from the work being reported.

- Methods (whenever applicable e.g. original article, review article): Specify the study's main and secondary objectives-usually identified as primary and secondary outcomes. Identify methods, equipment (give the manufacturer's name and address in parentheses), and procedures in sufficient detail to allow others to reproduce the results. Give references to established methods, including statistical methods; provide references and brief descriptions of methods that have been published but are not well known. Describe new or substantially modified methods, giving reasons for using them and evaluate their limitations. Include numbers of observations and the statistical significance of the findings where appropriate.

\section{- Selection and Description of Participants (under methods)}

Describe the selection of the subjects clearly, including eligibility and exclusion criteria and a description of the source population. If the study was done involving an exclusive population, for example in only one sex, authors should justify why, except in obvious cases, (e.g., prostate cancer)." Authors should define how they determined race or ethnicity and justify their relevance.

\section{Technical Information (under methods)}

Identify precisely all drugs and chemicals used, including generic name(s), dose(s), and route(s) of administration. Identify appropriate scientific names and gene names.

- Drugs must be referred to generically; all the usual trade names may be included in parentheses.

- Dosages should be quoted in metric units.

- Laboratory values should be in SI units with traditional unit in parentheses.

- Do not use patients' names, initials or hospital numbers to ensure anonymity.

Statistics (if applicable): Describe statistical methods which can be easily understood and verified by the reader. Use technical terms in its proper place, and where possible quantify readings and indicate errors of uncertainty and confidence intervals.

Discuss eligibility of experimental subjects. Give details about randomisation. Describe the methods for and success by any blinding of observations. Report treatment complications. Give number of observations. Report losses to observation (such as dropouts from a clinical trial). Avoid nontechnical uses of technical terms in statistics, such as "random" (which implies a randomising device), "normal", "significant", "correlations", and "sample". Define statistical terms, abbreviations, and symbols.

Results (whenever applicable e.g. original article, review article): Present results in logical sequence in the text, table and illustrations. Do not repeat in the text all the data in the Tables or Illustrations. Emphasise or summarise only important observations.

Provide data on all primary and secondary outcomes identified in the Methods Section. Extra or supplementary materials and technical details can be placed in an appendix where they will be accessible but will not interrupt the flow of the text, or they can be published solely in the electronic version of the journal.

Give numeric results not only as derivatives (for example, percentages) but also as the absolute numbers from which the derivatives were calculated, and specify the statistical significance attached to them, if any. Restrict tables and figures to those needed to explain the argument of the paper and to assess supporting data. Use graphs as an alternative to tables with many 
entries; do not duplicate data in graphs and tables. Avoid non technical uses of technical terms in statistics, such as "random" (which implies a randomizing device), "normal," "significant," "correlations," and "sample."

Separate reporting of data by demographic variables, such as age and sex, facilitate pooling of data for subgroups across studies and should be routine, unless there are compelling reasons not to stratify reporting, which should be explained.

Discussion (whenever applicable e.g. original article, review article): Authors should summarize what they found, similarities or differences compared to existing literature and why. The theoretical or clinical implications, limitations with regards to study design, methods, generalizability and internal validity should be discussed. It is useful to begin the discussion by briely summarizing the main endings, and explore possible mechanisms or explanations for these endings. Emphasize the new and important aspects of your study and put your findings in the context of the totality of the relevant evidence. State the limitations of your study, and explore the implications of your findings for future research and for clinical practice or policy. Discuss the influence or association of variables, such as sex and/or gender, on your findings, where appropriate, and the limitations of the data. Do not repeat in detail data or other information given in other parts of the manuscript, such as in the Introduction or the Results section.

- Conclusion: Summarize your main findings and its clinical implication, preferably in a single paragraph and more than 3-4 sentences. Link the conclusions with the goals of the study but avoid unqualified statements and conclusions not adequately supported by the data. In particular, distinguish between clinical and statistical significance, and avoid making statements on economic benefits and costs unless the manuscript includes the appropriate economic data and analyses. Avoid claiming priority or alluding to work that has not been completed. State new hypotheses when warranted, but label them clearly.

- $\quad$ References: The Vancouver style of referencing is adopted by the SFP Journal.

The author(s) is/ are responsible for the accuracy and completeness of the references, which should be identified in the text by superscript Arabic numerals in the order of first citation and noted in numerical order at the end of the text.

Digital Object Identifier (DOI) citation information must be included as a full DOI URL by prepending http://dx.doi.org/to any DOI reference. To identify a DOI reference, please visit CrossRef at http://www.crossref. org/guestquery/and enter in the reference information in the box provided to locate the DOI where available. Such DOI information will facilitate readers to trace referenced papers easily.

Where there are more than three authors, the first three should be named and then followed by et al.

Example:

Tan and Ho. Treat-to-target approach in managing modifiable risk factors of patients with coronary heart disease in primary care in Singapore: What are the issues? Asia Pacific Family Medicine, 2011;10:12. doi: 10. II86/ 1447-056X-10-12.

- Learning Points (for invited Family Physician Skills Course article): Include a minimum of 3 learning points as a take-home message forreaders.

- Tables: Tables should be submitted on a separate page. Label them in roman-numeric sequence [I, II, Illetc.] and ensure they are clear and with explanatory legends asrequired. Give each column a short or abbreviated heading. Place Table explanations in the footnotes, not in the heading. Explain in footnotes all non-standard abbreviations that are used in each Table.

- Illustrations: Illustrations must be submitted in a separate page, and should be provided whenever appropriate. Illustrations should be numbered consecutively in Arabic numerals (e.g. Fig. I, 2, 3) according to the order in which they have been first cited in the text. When required, it is the author's responsibility to obtain permission to reproduce illustrations. Authors need to ensure that photographs, illustrations and figures do not contain any information that will reveal the identities of the patients and authors. From I January 2012, all photographs and illustrations taken from any human subject must be accompanied by the respective endorsed consent form. Clear captions to the figures should be provided.

\section{Author Contributorship for Original Article Submission}

Author details must be included in the relevant fields when submitting an article. Only those who have made substantial contributions to the study and/ or preparation of the article should be acknowledged as authors and named in full. The SFP follows the International Committee of Medica Journal Editors (ICMJE) criteria pertaining to authorship (refer to http:// www.icmje.org/recommendations/browse/roles-and-responsibilities/ defining-the-role-of-authors-and-contributors.html). The precise role(s) of each author should be included in the 'contributorship' declaration.

\section{Plagiarism}

The Editorial Office has encountered cases where authors have copied entire paragraphs from previously published articles. Although these passages were duly cited and credited with reference sources derived from the articles, this has been found to be unacceptable by Journal standards. Authors are required to paraphrase all reference citations in their own words. This is necessary to prevent any future misunderstandings regarding plagiarism. Please be advised that all manuscripts submitted to the Journa will be screened for plagiarism using CrossCheck powered by iThenticate. In the rare case where a certain citation would lose its original meaning and essence if paraphrasing is attempted, the Journal requires authors to enclose the citation in quotation marks ("') to indicate that it is a direct quote from the source. However, excessive usage of such quotation marks is discouraged and should be utilised only when absolutely necessary.

In order to stem out this unethical practice of plagiarism, the Journal adopts a zero-tolerance stance toward wholesale copying of published works. Failure to comply with these instructions will result in the outright rejection of manuscripts without peer review.

\section{Declaration of Conflicts of Interest}

The SFP requires the author(s) to provide full and detailed declarations of any conflicts of interest. Where there are none, please use the following declaration: "The author(s) declare(s) that he/she/they has/have no conflict of interest in relation to this article."

\section{RECOMMENDED FORMAT FOR CASE RECORDS OF FAMILY MEDICINE SECTION}

The Case Records of Family Medicine is newly created series to encourage submissions from family medicine teaching programs, family medicine departments to submit cases of learning value to the Singapore Family Physician. Cases discussed during peer review learning, family medicine grand ward round teachings are just some examples that are suitable for this series. Authors planning to submit their case studies to the Case Records of Family Medicine section should structure their article according to these headings:

Title

- The title should define the key focus of the case study.

\section{Case Presentation:}

- The author(s) will provide a pertinent summary of the medical and / or psychosocial issue pertaining to the health or disease management of the case. It should cover the situation and relevant background of the case. Author(s) should conceal the identity of the subject and / or related or accompanying personnel : abbreviation should be used instead, if necessary.

\section{Diagnoses / Problems identified}

- The assessment of the diagnoses / problems identified will constitute a problem list and will serve as a focus for the management of the case. If the case was a diagnostic dilemma, the author(s) should showcase the diagnostic challenges and their work in narrowing to the correct diagnosis and / or differential diagnoses.

\section{Management of the case}

- This section covers the approach to the management of the case by the author(s). 
Literature review on latest evidence / guidelines (related to diagnosis and / or management)

- The author(s) should provide a literature review of current evidence / guidelines, if any, of the basis of the case's diagnosis / management, or to highlight the gaps of knowledge if such evidence is lacking.

- The author(s) will provide a concise summary of the lessons learnt from this case study.

Clinical Practice pointers (up to 3 )

- The author(s) will suggest ways to apply the new knowledge in clinical practice or to highlight the limitations of its applications, ifany.

\section{RECOMMENDED FORMAT FOR PRISM (Patients' Revelations as Insightful Studies of their Management) SECTION}

Authors planning to submit their case studies to the PRISM section should structure their article according to these headings:

\section{Title}

- The title should be framed into a question to define the key focus of the case study.

Patient's revelation: What happened?

- The author(s) will provide a concise description of the setting on which the subject raised his/her medical or psychosocial issue pertaining to their health or disease management. It should cover the background, encounter and interaction of patient with the healthcare professional (doctor, nurse or allied healthcare professional). Author(s) should conceal the identity of the subject and/or related or accompanying personnel: abbreviation should be used instead, if necessary.

Gaining insight: What are the issues?

- The issue(s) raised by the patient should be framed into question(s). The question(s) will constitute a problem list and will serve as a focus for the management of this subject.

Study the management: How do we apply in our clinical practice?

- This section covers the approach to the management of the subject by the author(s). The author(s) should provide a literature review of current evidence, if any, of the basis of the subject's management, or to highlight the gaps of knowledge if such evidence is lacking. The author(s) will suggest ways to apply the new knowledge in clinical practice or to highlight the limitations of its applications, if any.

Conclusion

- The author(s) will provide a concise summary of the lessons learnt from this case study.

The article submitted to the PRISM section should be written by not more than three authors. Each article should not exceed 2000 words. Photographs or charts may be included but should conform to the specific instructions for any other articles submitted to The Singapore Family Physician.

\section{Revised Manuscript Submission}

Manuscripts may be returned to their respective authors for revision. This will be accompanied by an Editor's email for which comments and recommendations may be made. The authors are advised to read and to take note of these comments carefully and to revise their articles accordingly. The authors need to reply to the editor's email to outline their response before the resubmission of the revised manuscript. They should exclude the identity of the authors and their institutions, as the email may be redirected to the reviewers during the resubmission process. The resubmitted manuscripts should include the revised complete version, as well as the anonymised version as before.

\section{Proofs}

Prior to publication, the Editorial Team will copy edit the article to fit the format of the Journal. The author will be sent the copy edited proof of the article, and the author should read carefully the proof and give comments and/or confirmation within 48 hours of receiving the proof. This will greatly facilitate the SFP to proceed to printing without delay, or to have to go to print without the corresponding author's comments.

\section{Reprints}

I complimentary copy of the article will be given to the authors. Additional copies can be ordered at authors' rates at time of printing.

\section{Correspondence \& Enquiries should be addressed to:}

The Honorary Editor, The Singapore Family Physician

College of Family Physicians Singapore

College of Medicine Building

16 College Road \#0I-02

Singapore 169854

Tel: $62230606 \quad$ Fax: 62220204

Email: editorialoffice@cfps.org.sg

\section{Circulation}

The Singapore Family Physician is published quarterly. It is circulated to all Fellows, Collegiate Members, Ordinary Members and Associate Members of the College of Family Physicians Singapore, and to private and institutional subscribers. It is also published online and can be found at www.cfps.org.sg.

The journal is also circulated to all relevant government, professional, medical and academic organisations in Singapore, sister Colleges overseas and to the World Organisation of National Colleges and Academies of General Practitioners/ Family Physicians (WONCA). 